\title{
First investigations on gas-phase mercury in two Italian cities
}

\author{
P. Avino ${ }^{1}$, M. Manigrasso ${ }^{1}$, C. Fanizza ${ }^{1}$, C. Vernale ${ }^{1}$, R Schirò ${ }^{1}$, \\ L. Giuliani ${ }^{2}$, R. Acerboni ${ }^{2}$, V. Annoscia ${ }^{3}$, C. Giannico ${ }^{3} \&$ F. Perri ${ }^{3}$ \\ ${ }^{I}$ Air Chemical Laboratory, DIPIA, ISPESL, Rome, Italy \\ ${ }^{2}$ Dipartimento di Venezia, ISPESL, Venice, Italy \\ ${ }^{3}$ Dipartimento di Taranto, ISPESL, Taranto, Italy
}

\begin{abstract}
Mercury is an element naturally present in the biosphere of both natural and anthropogenic origins. From the chemical point of view mercury is present in the atmosphere in gaseous form as elementary mercury and Reactive Gaseous Mercury and adsorbed onto particulate matter over that in other forms in ultratrace. From the toxicological point of view mercury is extremely toxic, reaches all the organs and it is also quickly absorbed by the lungs. In this study seasonal study campaigns were performed during 2005-2006 in two urban areas of different Italian cities, Taranto and Venice, to investigate the levels and behavior of gaseous-phase mercury. For the sampling and analysis a portable instrument was used based on the atomic absorption methodology with the background correction through the Zeeman effect. No relevant situations for human health were found (the levels range between 1 and $15 \mathrm{ng} / \mathrm{m}^{3}$ ).

Keywords: mercury, urban pollution, human health, meteorological stability.
\end{abstract}

\section{Introduction}

Mercury is an element naturally present in biosphere: it can be of both natural (e.g. volcanic eruption, etc.) and anthropogenic (e.g. pig iron production, power plants or heat production, sanitary waste incinerators, etc.) origins. It is redistributed in atmosphere, in water and in soil doing so a very complex cycle of which only some passages are known while many other attend to be clarified. The interest for a greater knowledge of the mercury cycle in biosphere is 
connected to its level: in fact, because it represents a real hazard for human health it should be necessary to keep low its levels.

From the chemical point of view mercury is present in atmosphere in gaseous forms as elementary mercury $\left(\mathrm{Hg}^{0}\right)$ and Reactive Gaseous Mercury, RGM (e.g. $\mathrm{HgCl}_{2}$ ), and adsorbed onto particulate matter (Total Particulate Mercury, TPM) over that in other forms in ultra-trace (e.g. methylated form) [1]. From the toxicological point of view mercury is extremely toxic. Elemental mercury vapor is highly toxic and is very hazardous to human health [2-4]. Mercury reaches all the organs (particularly, the kidneys) and besides it is quickly absorbed by the lungs [5]. As reported from other authors, the exposition risk is not only for people professionally exposed but also for people who reside or work in contaminated areas and individuals with amalgam fillings [6,7].

Table 1 shows the levels of the different species of mercury reported in literature.

Table 1: Levels of the different species of mercury from literature. a: expressed as $\mathrm{pg} / \mathrm{m}^{3}$.

\begin{tabular}{|l|c|c|}
\hline Species & $\begin{array}{c}\text { Air } \\
\left(\mathrm{ng} / \mathrm{m}^{3}\right)\end{array}$ & $\begin{array}{c}\text { Wet dry } \\
(\mathrm{ng} / \mathrm{L})\end{array}$ \\
\hline Total Hg & $1.2-3.7$ & $5-80$ \\
\hline $\mathrm{Hg}^{0}$ & $1.0-3.6$ & $<0.005$ \\
\hline $\mathrm{RGM}$ & $1-50^{\mathrm{a}}$ & $5-50$ \\
\hline $\mathrm{TPM}$ & $1-50^{\mathrm{a}}$ & $5-50$ \\
\hline Methylmercury & $1-20^{\mathrm{a}}$ & $0.005-0.5$ \\
\hline
\end{tabular}

Finally, a greater knowledge of the mercury cycle in biosphere is connected to the necessity to maintain low its level since it represents a real danger for human health according to two historical studies (Minamata, Japan, from 1953 to 1960 and Iraq population in 1971) allowing data acquisition of great importance on the toxicity from mercury, and then from other numerous following $[8,9]$.

For this reasons the World Health Organization (WHO) has more times affirmed the necessity to keep a high level of attention to the mercury exposure recommending also monitoring such pollutant $[2,3]$.

In this paper some study campaigns have been performed during the period April-October 2006 in downtown of two Italian cities, Mestre (a few kms away from Venice) and Taranto, in order to investigate the levels and the behavior of the total gaseous-phase mercury ( $\mathrm{Hg}^{0}$ and Reactive Gaseous Mercury).

\section{Experimental part}

\subsection{Sampling sites}

The two cities, Mestre and Taranto (Figure 1), have been chosen on the basis of their different urbanization: presence of industrial ports, different anthropogenic activities of great relief, urban installations not situated close to natural mercury 
sources. In particular, Mestre is located in the North Italy whereas Taranto in the South Italy and in a region where, except Taranto itself, there are no strong anthropogenic activities.

The contexts studied can be considered as example of specific anthropogenic pollution, allowing so to collect data that can contribute to a best knowledge of the mercury presence in biosphere.

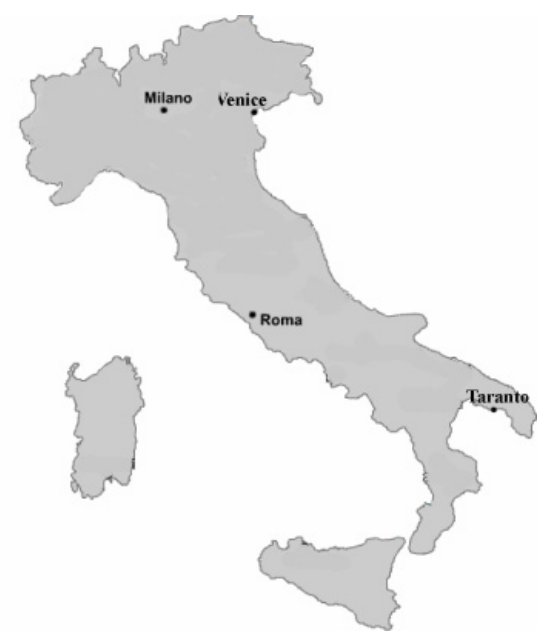

Figure 1: Map of Italy where Venice and Taranto are evidenced (Mestre is a few kms away from Venice).

\subsection{Instrumental equipment}

An RA-915+ atomic mercury spectrometer with an RP-91 attachment unit (Lumex, St. Petersburg, Russia) has been used as a mercury detector. A deep description of this instrument is reported by Pogarev et al. [4]. Here, we would like to briefly resume it. The RA-915+ is used for continuous mercury determination in air and for rapid analysis of solid and liquid samples. The spectrometer was placed in downtown of each city to investigate the mercury level and its behavior. Air flows continuously through the analytical cell. The blank signal is regularly checked by passing the air through a special filter with the Hg-absorption efficiency of $98-99 \%$. The mercury concentration is measured every $15 \mathrm{~s}$ and processed.

The combination of the Zeeman Atomic Absorption Spectrometry using High Frequency Modulate light polarization (ZAAS-HFM) [10] and a multipath cell allows direct selective measuring of mercury at the background level up to 1 $\mathrm{ng} / \mathrm{m}^{3}$ with a response time of $1 \mathrm{~s}$. The low detection limit (LOD) provides detection of remote or buried sources and high selectivity enables tracing mercury haloes in the presence of complex volatile compounds in air [11]. 


\section{Results and discussion}

From an analytical point of view it is interesting to investigate the possibility of this instrument that allows one to analyze the mercury level every $15 \mathrm{~s}$ in air. The LOD for this equipment has been established at $1 \mathrm{ng} / \mathrm{m}^{3}$, analyzing the standards and the comparison with other spectrometric techniques.

Typical daily Reactive Gaseous Mercury concentration trends in Mestre (North Italy) and Taranto (South Italy) are reported in Figures 2 and 3, respectively.

First of all, analyzing Figures 2 and 3, it can be possible to evidence quite similar average mercury levels in the two different zones investigated. In particular, extrapoling for the whole period, average levels of $2.36 \mathrm{ng} / \mathrm{m}^{3}$ and $2.92 \mathrm{ng} / \mathrm{m}^{3}$ for Venice e Taranto, respectively, are found.

Furthermore, from Figure 2 the daily RGM trend is almost the same and no typical behavior can be noted: the only interesting data is the peak on the early morning of October $12^{\text {th }}$ when the mercury level reaches almost $11 \mathrm{ng} / \mathrm{m}^{3}$. In particular, this level is reached for a while due maybe to a local emission. Figure 3 shows a situation little bit different where a regular trend during the days can be evidenced: the daily behavior is characterized by growing levels during the early morning with a relative maximum peaks during the midday and, after it, by decreasing levels down to the afternoon when the minimum relative quote is reached.

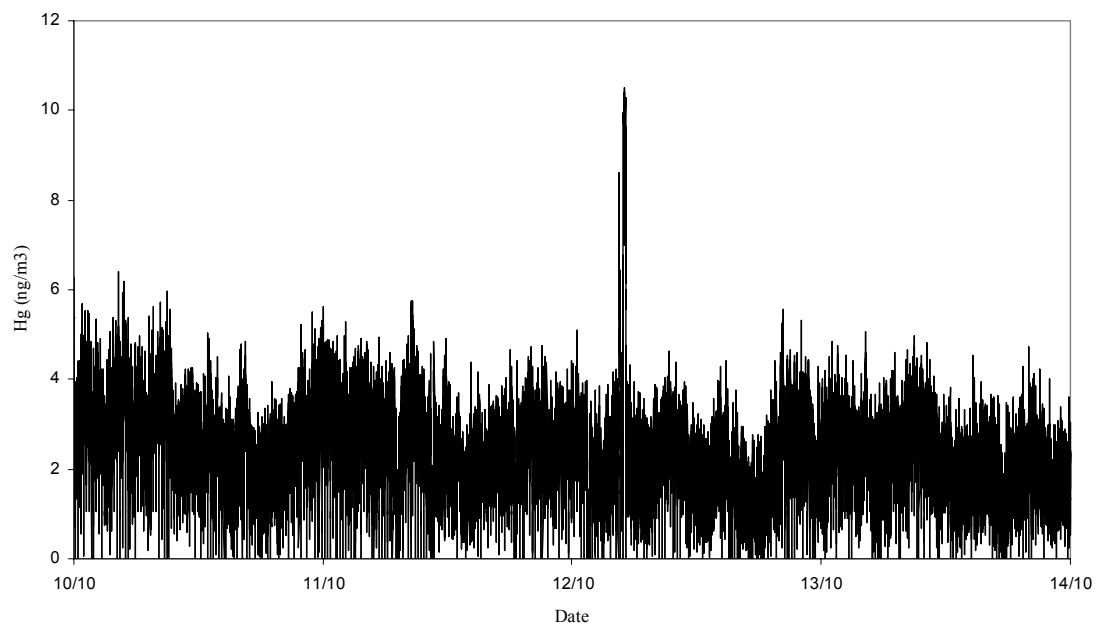

Figure 2: Daily RGM concentration trends in downtown Mestre (October 2006).

Furthermore, the maximum peaks recorded every midday demonstrate regular emissions both from same source and same direction (W-SW). The identification of this source is not easy to individuate because it should be necessary to know 
exactly the anthropogenic activities (and eventually the presence of particular natural sources) in that area but it should be considered that this emission is not so strong and consequently the maximum reached peak is $8 \mathrm{ng} / \mathrm{m}^{3}$.

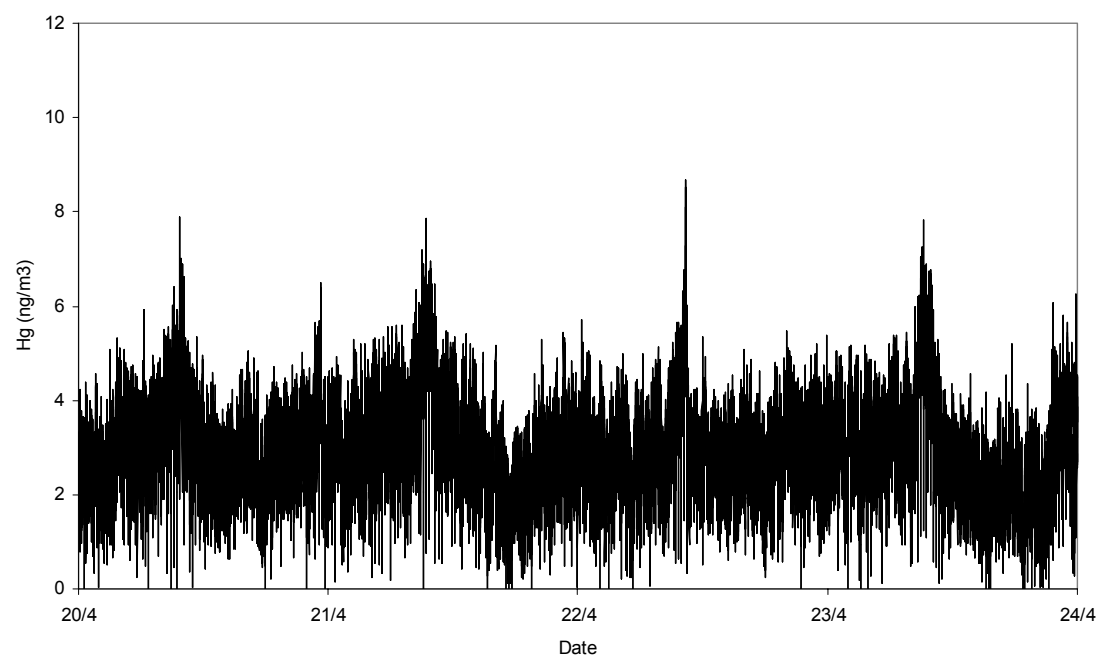

Figure 3: Daily RGM concentration trends in downtown Taranto (April 2006).

\section{Conclusions}

This paper reports the preliminary results of an investigation on the mercury levels and behavior carried out in two Italian cities. No relevant situations for human health were found (the levels range between 1 and $15 \mathrm{ng} / \mathrm{m}^{3}$ according the areas). Finally, the mercury levels and behavior have been discussed to the atmospheric stability conditions. It should be noted that these data represent the first systematic investigation of this pollutant in Italian urban cities.

\section{References}

[1] Carpi, A., Mercury from combustion sources: a review of the chemical species emitted and their transport in the atmosphere. Water Air and Soil Pollution, 98, pp. 241-254, 1997.

[2] Environmental Health Criteria 1, Inorganic Mercury; World Health Organization (WHO), Geneva, 1979.

[3] Environmental Health Criteria 118, Inorganic Mercury; World Health Organization (WHO), Geneva, 1991.

[4] Pogarev, S.E., Ryzhov, V.V., Mashyanov, N.R., Sholupov, S. \& Zharskaya V., Direct measurement of the mercury content of exhaled air: a new approach for determination of the mercury dose received. Analytical and Bioanalytical Chemistry, 374, pp. 1039-1044, 2002. 
[5] Falnoga, I., Tusek-Znidaric, M., Horvat, M. \& Stegnar P., Environmental Research, A84, pp. 211-218, 2000.

[6] Pogarev, S.E., Ryzhov, V.V., Mashyanov, N.R. \& Sobolev, M.B., Mercury values in urine from inhabitants of St. Petersburg. Water, Air and Soil Pollution, 97, pp. 193-198, 1997.

[7] Barregard, L., Sallsten, G. \& Jarvholm, B., Occupational Environmental Medicine, 52, pp. 124-128, 1995.

[8] http://www.whitehouse.gov/ccq/clean-air.html

[9] Ambient air pollution by mercury (Hg). Position paper; European Commission, Brussels, 2001.

[10] Sholupov, S.E. \& Ganeyev. A.A., Zeeman Absorption Spectrometry using High Frequency Modulate light polarization. Spectrochimica Acta, 50B, pp. 1227-1236, 1995.

[11] Ryzhov, V.V., Mashyanov, N.R., Ozerova, N.A. \& Pogarev, S.E., Regular variations of the mercury concentration in natural gas. The Science of Total Environment, 304, pp. 145-152, 2003. 